\title{
Suzuki Reaction of Aryl Bromides Using a Phosphine-Free Magnetic Nanoparticle-Supported Palladium Catalyst
}

\author{
Nghia T. BUI, Trung B. DANG, Ha V. LE, Nam T. S. PHAN* \\ Department of Chemical Engineering, HCMC University of Technology, VNU-HCM, 268 Ly Thuong Kiet, \\ District 10, Ho Chi Minh City, Viet Nam
}

\begin{abstract}
A palladium catalyst immobilized on superparaganetic nanoparticles was prepared with a palladium loading of $0.30 \mathrm{mmol} / \mathrm{g}$. The catalyst was characterized using X-ray diffraction, scanning electron microscopy, transmission electron microscopy, vibrating sample magnetometry, thermogravimetric analysis, Fourier transform infrared, atomic absorption spectrophotometry, and nitrogen adsorption. The immobilized palladium catalyst was an efficient catalyst without added phosphine ligands for the Suzuki cross-coupling reaction of several aryl bromides with phenylboronic acid. The recovery of catalyst was simply by magnetic decantation in the presence of a magnet. The immobilized palladium catalyst can be reused many times without significant degradation in catalytic activity. No leaching of active palladium species into the reaction solution was detected.
\end{abstract}

Key words: superparamagnetic nanoparticle; Suzuki reaction; palladium; aryl bromide

CLC number: O643 Document code: A

Received 30 May 2011. Accepted 20 July 2011.

*Corresponding author.Tel: +84-8-917416018; Fax:+84-8-38637504; E-mail: ptsnam@hcmut.edu.vn

This work was supported by the Ho Chi Minh City Department of Science and Technology, Viet Nam.

English edition available online at Elsevier ScienceDirect (http://www.sciencedirect.com/science/journal/18722067).

Biaryl units as molecular components in biologically active molecules and functional polymers have attracted enormous interest [1,2]. The Suzuki cross-coupling reaction is an increasingly popular approach for the construction of unsymmetrical biaryl compounds since the organoboranes used are environmentally safer than other organometallic reagents [3]. Toxic and expensive homogeneous palladium phosphine complexes, which are rarely recoverable [4], are used as the catalysts for the Suzuki reaction [5-7]. The phosphines can be more costly than even the palladium in some cases [8]. From economic and environmental considerations, it is desirable to use a solid catalyst that does not have the hazardous phosphine additives as a green alternative to the conventional homogeneous processes for the Suzuki reaction [8,9]. Several phosphine-free solid palladium catalysts have been investigated for the Suzuki reaction, e.g., palladium species immobilized on polymer [10-13], silica [14-21], zeolite [22-24], hybrid organicinorganic material $[25,26]$, and palladium nanoparticle-based catalysts [27-31].

Nanoparticles have attracted significant interest as efficient supports for homogeneous catalyst immobilization $[32,33]$. When the size of the support is decreased to the nanometer scale, the activity of the supported catalyst can be dramatically improved compared to homogeneous catalysts immobilized on conventional supports under condi- tions where internal pore diffusion is rate limiting [32,34]. However, the facile separation and recycling of the nanoparticle materials from the reaction media still remains a challenge [34]. The problem can be solved by employing magnetic supports that allow the catalyst to be easily separated from the liquid reaction media by a magnet $[35,36]$. Magnetic nanoparticles have been utilized as catalyst supports for several organic transformations [36,37] such as olefin hydroformylation [38], alcohol hydrogenation [39], olefin hydrogenation [40], asymmetric hydrogenation $[41,42]$, aldol reaction [43], Suzuki and Heck reactions [44-48], Sonogashira and Carbonylative Sonogashira reactions [44,49,50], Knoevenagel condensation [34], dehalogenation [51], oxidation [52-54], ring-opening polymerization of $\varepsilon$-caprolactone [55], ring-closing metathesis [56], cycloaddition reaction [57], and as supports for biocatalysts [58-61]. In this paper, we report the Suzuki cross-coupling reaction of aryl bromides with phenylboronic acid by a palladium catalyst without added phosphine ligands immobilized on superparamagnetic nanoparticles. The magnetic catalyst can be isolated from the reaction mixture by simple magnetic decantation, and can be reused without significant degradation in activity.

\section{Experimental}




\subsection{Materials and instrumentation}

Chemicals were purchased from Sigma-Aldrich, Fisher, and Merck and used as received without further purification unless otherwise noted. Distilled water was purged with nitrogen for $2 \mathrm{~h}$ prior to use. A Fischer Scientific FS60H ultrasonic bath was used to sonicate samples. Fourier transform infrared (FT-IR) spectra were obtained on a Bruker TENSOR37 instrument. The samples were dispersed on potassium bromide pallets. Magnetic properties were measured with a PPMS 6000 vibrating sample magnetometer (VSM) at $32{ }^{\circ} \mathrm{C}$. Samples were sonicated in dimethylformamide for $30 \mathrm{~min}$ before measurements were taken. Scanning electron microscopy (SEM) studies were conducted on a JSM 740 scanning electron microscope. Transmission electron microscopy (TEM) studies were performed using a JEOL JEM 1400 transmission electron microscope at $100 \mathrm{kV}$. The samples were dispersed on holey carbon grids for TEM observation. Nitrogen physisorption measurements were conducted using a Quantachrome 2200e system. Samples were pretreated by heating under vacuum at $150{ }^{\circ} \mathrm{C}$ for $3 \mathrm{~h}$. Elemental analysis with atomic absorption spectroscopy (AAS) was performed on an AA-6800 Shimadzu instrument. X-ray diffraction (XRD) patterns were recorded using a $\mathrm{Cu} K_{\alpha}$ radiation source on a D8 Advance Bruker powder diffractometer.

A Netzsch Thermoanalyzer STA 409 was used for thermogravimetric analysis (TGA) with a heating rate of 10 ${ }^{\circ} \mathrm{C} / \mathrm{min}$ in air. Gas chromatographic (GC) analyses were performed using a Shimadzu GC 17-A chromatograph equipped with a flame ionization detector (FID) and a DB-5 column (length $=30 \mathrm{~m}$, inner diameter $=0.25 \mathrm{~mm}$, and film thickness $=0.25 \mu \mathrm{m}$ ). The temperature program for the GC analysis was from 60 to $140{ }^{\circ} \mathrm{C}$ at $10^{\circ} \mathrm{C} / \mathrm{min}$, held at $140{ }^{\circ} \mathrm{C}$ for $1 \mathrm{~min}$, heated from 140 to $300{ }^{\circ} \mathrm{C}$ at $50{ }^{\circ} \mathrm{C} / \mathrm{min}$ and held at $300{ }^{\circ} \mathrm{C}$ for $3 \mathrm{~min}$. The inlet and detector temperatures were set at $300{ }^{\circ} \mathrm{C}$. $n$-Hexadecane was used as an internal standard to calculate reaction conversions. GC-MS analyses were performed using a Hewlett Packard GC-MS 5972 instrument with a RTX-5MS column (length $=30 \mathrm{~m}$, inner diameter $=0.25 \mathrm{~mm}$, and film thickness $=0.5 \mu \mathrm{m})$. The temperature program for GC-MS analysis was from 60 to $280{ }^{\circ} \mathrm{C}$ at $10{ }^{\circ} \mathrm{C} / \mathrm{min}$ and held at $280{ }^{\circ} \mathrm{C}$ for $2 \mathrm{~min}$. The inlet temperature was set at $280{ }^{\circ} \mathrm{C}$. MS spectra were compared with the spectra in the NIST library.

\subsection{Synthesis of amino-functionalized magnetic nanoparticles}

The superparamagnetic nanoparticles were synthesized and functionalized with $N$-[3-(trimethoxysilyl)propyl] ethylenediamine by a slight modification of a reported pro- cedure $[34,62]$. The nanoparticles $(2.5 \mathrm{~g})$ were dispersed in a mixture of ethanol and water $(400 \mathrm{ml}, 1: 1$ by volume). Ammonium hydroxide ( $40 \mathrm{ml}, 25 \% \mathrm{v} / \mathrm{v}$ aqueous solution) was added, and the mixture was stirred vigorously at $60{ }^{\circ} \mathrm{C}$ for $24 \mathrm{~h}$ under argon. The nanoparticles were washed with copious amounts of deionized water, ethanol, and $n$-hexane by magnetic decantation. The resulting product was redispersed in a mixture of ethanol and water $(400 \mathrm{ml}, 1: 1$ by volume), and sonicated for $30 \mathrm{~min}$ at room temperature. $\mathrm{N}$-[3-(trimethoxysilyl)propyl]ethylenediamine (2.8 g) was then added, and the solution was heated at $60{ }^{\circ} \mathrm{C}$ with vigorous stirring for $36 \mathrm{~h}$ under argon. The final product was washed with copious amounts of deionized water, ethanol, and $n$-hexane by magnetic decantation, and dried under vacuum at room temperature overnight to yield diamino-functionalized magnetic nanoparticles (1.98 g).

\subsection{Synthesis of palladium catalyst immobilized on superparamagnetic nanoparticles}

The diamino-functionalized magnetic nanoparticles (1.82 g) were added to a round-bottom flask containing ethanol $(99.5 \%, 270 \mathrm{ml})$ and 2-acetyl pyridine (18 $\mathrm{ml}, 150 \mathrm{mmol})$ $[63,64]$. The resulting mixture was sonicated for $30 \mathrm{~min}$, and then heated under reflux with rapid stirring for $36 \mathrm{~h}$ under argon. After that, the reaction mixture was cooled to room temperature and the solid was separated by magnetic decantation. The magnetic solid was then redispersed in ethanol and hexane and sonicated for $30 \mathrm{~min}$ at room temperature. The product was then separated by magnetic decantation and dried under vacuum at room temperature to yield the immobilized Schiff base (1.80 g). The immobilized Schiff base $(1.60 \mathrm{~g})$ was added to the round-bottom flask containing a solution of palladium acetate $(0.1815 \mathrm{~g}, 0.80$ $\mathrm{mmol})$ in acetone $(280 \mathrm{ml})$. The mixture was then stirred vigorously at room temperature for $36 \mathrm{~h}$ under argon. The solid was separated by magnetic decantation, redispersed in acetone, sonicated for $30 \mathrm{~min}$ at room temperature, and then separated by magnetic decantation. The magnetic catalyst was washed with copious amounts of acetone and dried under vacuum at room temperature to yield the immobilized palladium catalyst $(1.50 \mathrm{~g})$.

\subsection{Catalytic studies}

Unless otherwise stated, a mixture of 4'-bromoacetophenone (0.2149 g, $1.08 \mathrm{mmol})$, phenylboronic acid (0.1975 $\mathrm{g}, 1.62 \mathrm{mmol}), \mathrm{K}_{3} \mathrm{PO}_{4}(0.8628 \mathrm{~g}, 3.24 \mathrm{mmol})$, and $n$-hexadecane $(0.12 \mathrm{ml})$ as the internal standard in dimethylformamide $(5 \mathrm{ml})$ were added to a round-bottom flask containing the required amount of the immobilized palladium catalyst. The flask was heated at the required 
temperature with magnetic stirring. Reaction conversions were monitored by withdrawing aliquots $(0.1 \mathrm{ml})$ from the reaction mixture at different time intervals and quenching with water $(1 \mathrm{ml})$. The organic components were extracted into diethylether $(2 \mathrm{ml} \times 2)$, dried over $\mathrm{Na}_{2} \mathrm{SO}_{4}$, and analyzed by GC with $n$-hexadecane as the reference. The product identity was also further confirmed by GC-MS.

\section{Results and discussion}

\subsection{Catalyst synthesis and characterization}

Superparamagnetic nanoparticles were synthesized by a microemulsion method [34,65]. The elemental analysis (AAS) of the particles showed the $\mathrm{Co}: \mathrm{Fe}$ molar ratio of 1:2.08 corresponding to the $\mathrm{CoFe}_{2} \mathrm{O}_{4}$ structure. The synthesis of $\mathrm{Co}_{x} \mathrm{Fe}_{3-x} \mathrm{O}_{4}$ superparamagnetic nanoparticles with different $\mathrm{Co}$ :Fe ratios was previously reported [66]. We recently prepared a palladium catalyst immobilized on $\mathrm{CoFe}_{2} \mathrm{O}_{4}$ superparamagnetic nanoparticles via silane and Schiff base chemistry using an approach developed by Clark and coworkers $[63,64]$ (catalyst A, Scheme 1), which was used without added phosphine ligands for the Sonogashira reaction [50]. The use of superparamagnetic nanoparticles as catalyst support offers advantages in catalyst separation and recycling over similar silica-based catalysts. Interestingly, initial experimental results showed that the catalytic activity was significantly improved when the tether in the catalyst structure was extended by using $N$-[3-(trimethoxysilyl)propyl]ethylenediamine instead of 3-(trimethoxysilyl)propylamine in the catalyst preparation (catalyst B, Scheme 1). We therefore decided to use the latter catalyst for further studies.

The immobilized palladium catalyst was characterized using a variety of different techniques as previously reported [50]. VSM analysis showed that the immobilized palladium catalyst was superparamagnetic. The particle diameters were approximately $30-40 \mathrm{~nm}$ from SEM and TEM (Fig. 1) micrographs of the particles. However, particle agglomeration was clearly observed, and the primary particle size was likely to be closer to $5-10 \mathrm{~nm}$ in diameter.

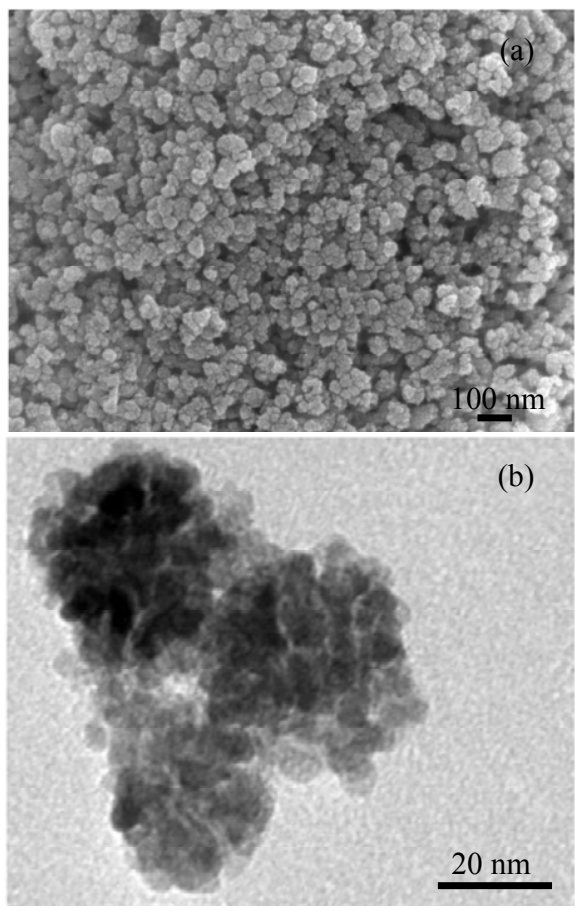

Fig. 1. SEM (a) and TEM (b) micrographs of the functionalized superparamagnetic nanoparticles.

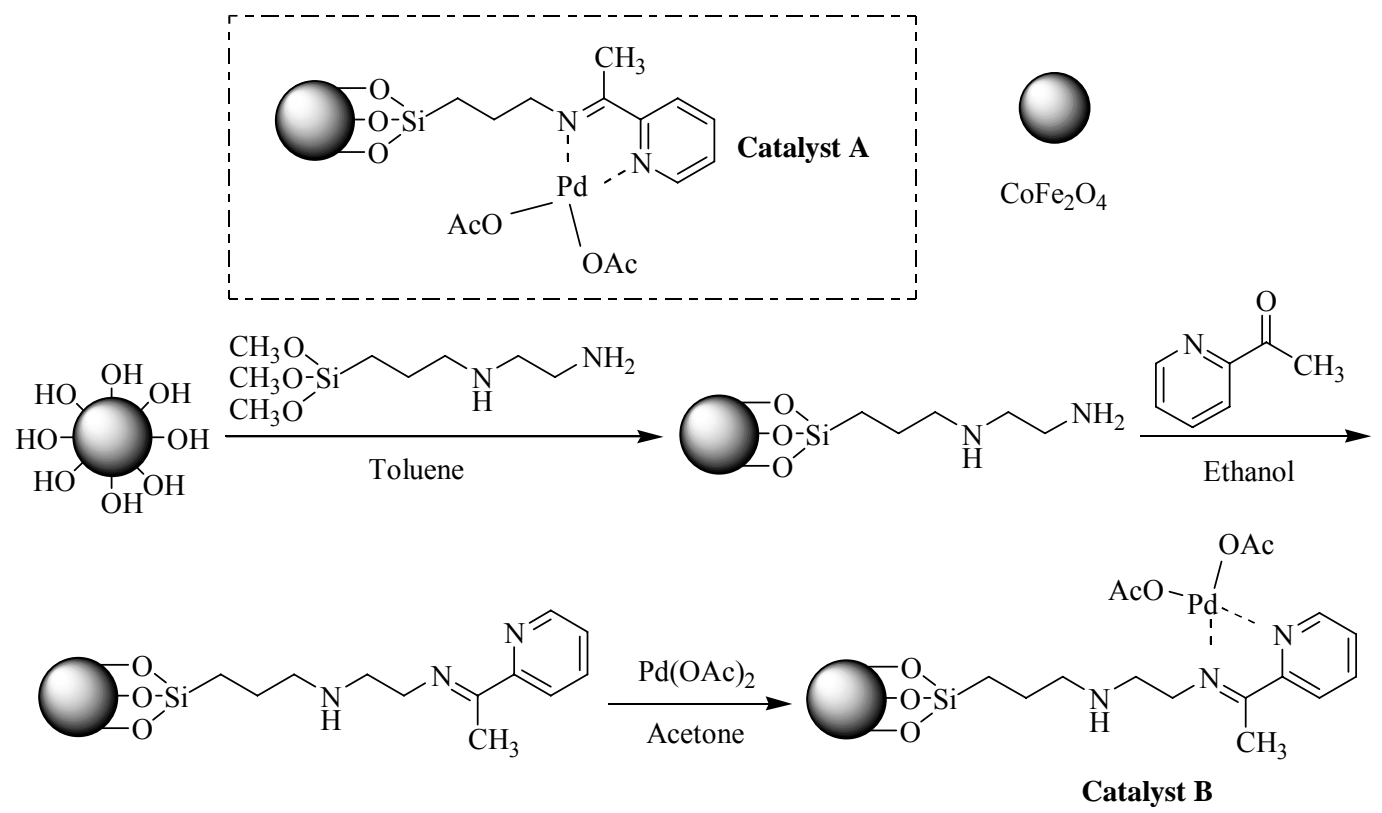

Scheme 1. Synthesis of the palladium catalyst immobilized on superparamagnetic nanoparticles (Catalyst B). 
Most oxide particles, regardless of composition, aggregate on TEM grids, and thus, the TEM images do not imply that the nanoparticles aggregate in solution [34].

XRD patterns of the superparamagnetic nanoparticles were consistent with those previously reported in the literature $[35,67,68]$ (Fig. 2). The BET surface areas were 150.44 $\mathrm{m}^{2} / \mathrm{g}$ for the superparamagnetic nanoparticles, which was in good agreement with the literature where BET surface areas ranged from $120 \mathrm{~m}^{2} / \mathrm{g}$ to $200 \mathrm{~m}^{2} / \mathrm{g}[35,67]$.

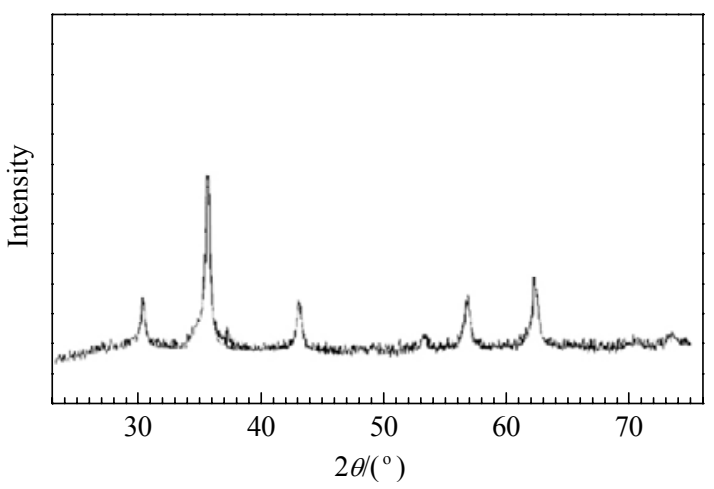

Fig. 2. XRD pattern of the immobilized palladium catalyst.

The significant features in the FT-IR spectra of the immobilized palladium catalyst were the appearance of peaks near $1015 \mathrm{~cm}^{-1}$ for $\mathrm{Si}-\mathrm{O}$ stretching. There were also peaks near $2900 \mathrm{~cm}^{-1}$ due to the $-\mathrm{CH}_{2}$ and aromatic $\mathrm{C}-\mathrm{H}$ stretching vibrations, and the peak of the imine $\mathrm{C}=\mathrm{N}$ stretching vibration near $1600 \mathrm{~cm}^{-1}$ which was overlapped with the $\mathrm{O}-\mathrm{H}$ deformation vibration (Fig. 3) [68,69].

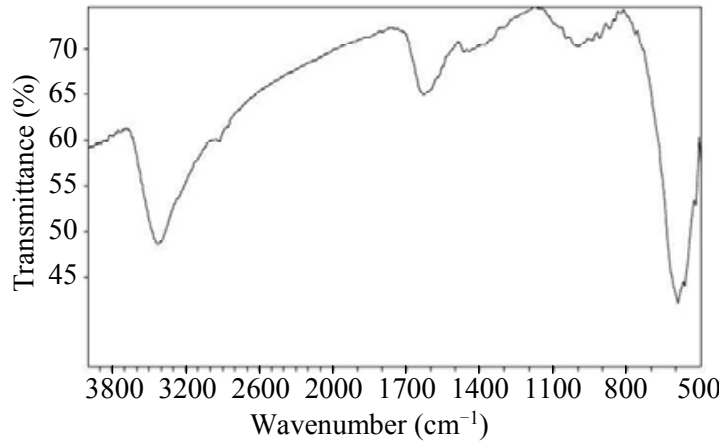

Fig. 3. FT-IR spectrum of the immobilized palladium catalyst.

TGA results exhibited differences among the unfunctionalized nanoparticles, the immobilized Schiff base ligand, and the immobilized palladium catalyst (Fig. 4). The TGA result showed that a diamine loading of $0.50 \mathrm{mmol} / \mathrm{g}$ was achieved for the diamine-functionalized nanoparticles. The elemental analysis indicated a nitrogen loading of 1.04 $\mathrm{mmol} / \mathrm{g}$, corresponding to $0.52 \mathrm{mmol} / \mathrm{g}$ of the diamine immobilized on the superparamagnetic nanoparticles. The TGA analysis of the immobilized Schiff base ligand showed
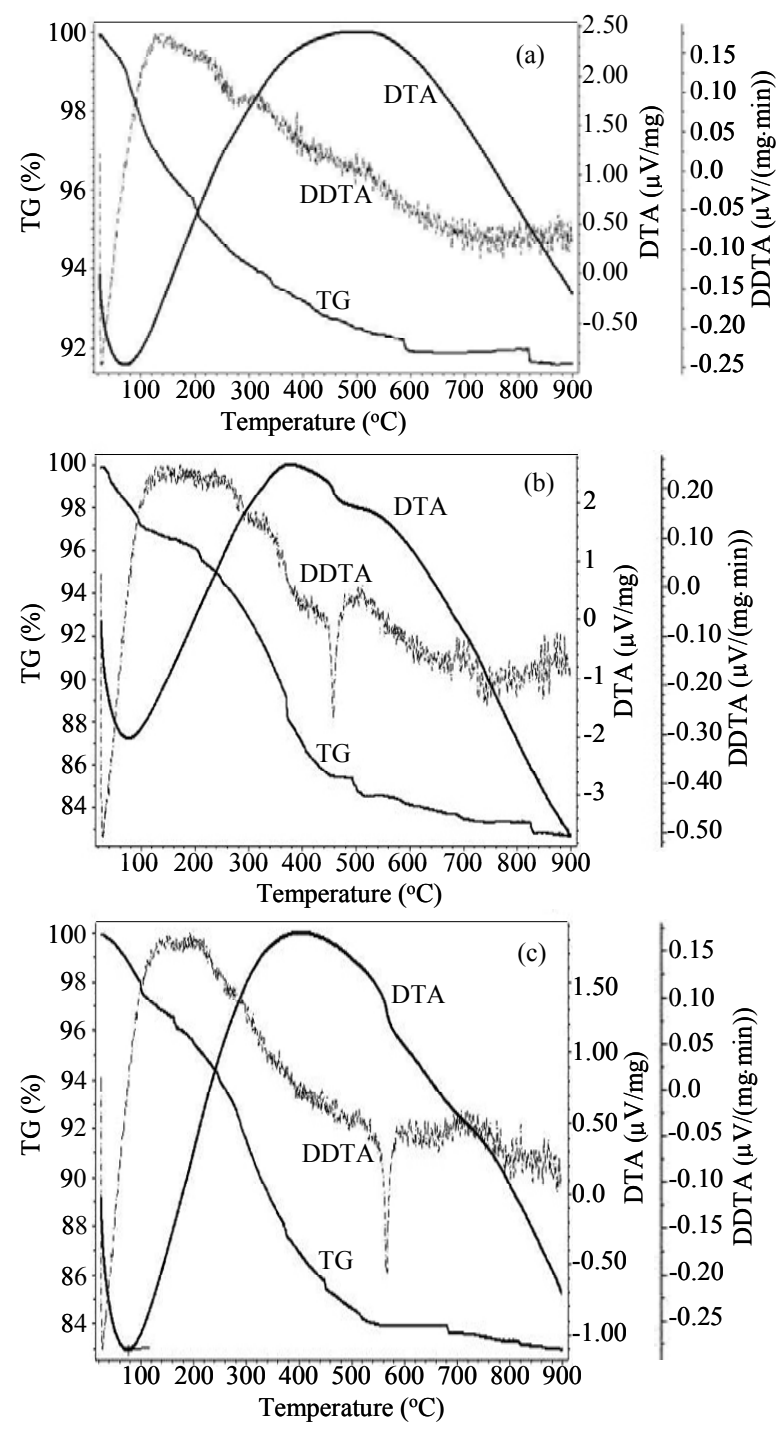

Fig. 4. TGA profiles of the unfunctionalized superparamagnetic nanoparticles (a), immobilized Schiff base ligand (b), and immobilized palladium catalyst (c).

a Schiff base loading of $0.48 \mathrm{mmol} / \mathrm{g}$. The AAS analysis of the immobilized palladium catalyst exhibited a palladium loading of $0.30 \mathrm{mmol} / \mathrm{g}$. The metal loadings of several immobilized palladium catalysts for cross-coupling reactions were previously reported to be in the range of $0.1-0.5$ $\mathrm{mmol} / \mathrm{g}$ [8]. No meaningful data for the palladium immobilization was obtained from the XRD and FT-IR results due to the low loading of the metal. It was also not possible to monitor changes on the surface of the particles using electron microscopy techniques because the particles were black. Therefore, proof that the palladium was immobilized on the superparamagnetic nanoparticles came from the AAS data of the catalyst, from leaching studies which showed negligible activity of the reaction solution after the solid catalyst was removed, and from the fact that the catalyst can 
be recovered and reused several times without significant degradation in catalytic activity.

\subsection{Catalytic studies}

The immobilized palladium complex catalyst was initially assessed for its activity in the Suzuki cross-coupling reaction between 4'-bromoacetophenone and phenylboronic acid to form 4-acetylbiphenyl as the principal product (Scheme 2). As dimethylformamide (DMF) is the solvent of choice for cross-coupling reactions [8], it was decided to carry out the Suzuki reaction in DMF at $100{ }^{\circ} \mathrm{C}$ using 0.1 $\mathrm{mol} \%$ of the immobilized palladium catalyst without added phosphine ligands. As the presence of a base was necessary in the Suzuki catalytic cycle $[3,6,8]$, the effect of bases on the reaction conversion was investigated by carrying out the reaction in the presence of $\mathrm{K}_{3} \mathrm{PO}_{4}, \mathrm{~K}_{2} \mathrm{CO}_{3}, \mathrm{CH}_{3} \mathrm{COONa}$, and triethylamine. $\mathrm{K}_{2} \mathrm{CO}_{3}$ has been effectively employed in several Suzuki cross-coupling processes using homogeneous palladium phosphine complexes as catalysts [3]. In our research, however, the immobilized palladium catalyst in the presence of $\mathrm{K}_{2} \mathrm{CO}_{3}$ gave the Suzuki reaction with a significant slower rate than with the reaction using $\mathrm{K}_{3} \mathrm{PO}_{4}$. Triethylamine and $\mathrm{CH}_{3} \mathrm{COONa}$ were unsuitable for the immobilized palladium catalyst in the Suzuki reaction. It was previously reported that weaker bases gave better results for less hindered arylboronic acids in several Suzuki reactions [70]. Although phenylboronic acid is not sterically hindered, the reaction using $\mathrm{K}_{3} \mathrm{PO}_{4}$ gave significantly better conversions than the reactions using weaker bases, and a quantitative conversion was achieved after $1 \mathrm{~h}$ (Fig. 5). Indeed, $\mathrm{K}_{3} \mathrm{PO}_{4}$ has been found to be the base of choice for the Suzuki reaction in some cases $[12,47,71,72]$. It was therefore decided to use $\mathrm{K}_{3} \mathrm{PO}_{4}$ for the reaction in further experiments.

To investigate the effect of temperature on the reaction conversion, the reaction was carried out in DMF at a catalyst concentration of $0.1 \mathrm{~mol} \%$ in the presence of $\mathrm{K}_{3} \mathrm{PO}_{4}$ as the base. The temperature range of $80-120{ }^{\circ} \mathrm{C}$ was previously employed for several Suzuki cross-coupling processes with different reactions and catalysts $[3,5,6,73,74]$. It was also reported that the Suzuki reaction using phosphinebased catalysts can occur at room temperature although a

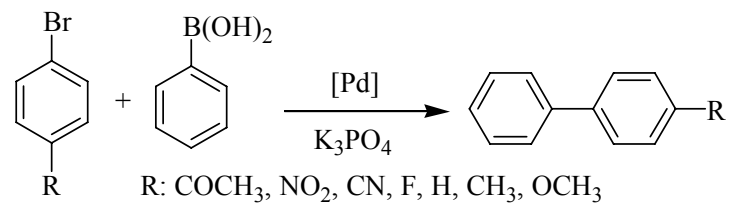

Scheme 2. Suzuki reaction of aryl bromides and phenylboronic acid using the palladium catalyst immobilized on the superparamagnetic nanoparticles.

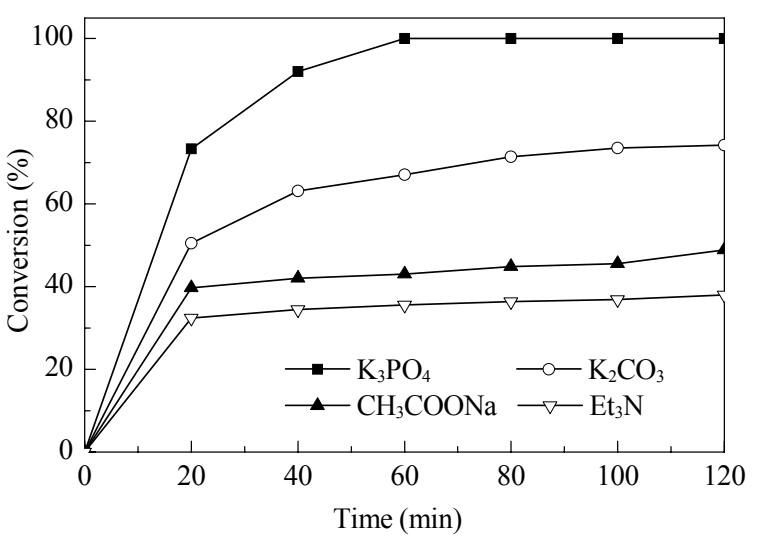

Fig. 5. Effect of different bases on reaction conversion.

longer reaction time was required $[75,76]$. In our study, it was found that the Suzuki reaction using the immobilized palladium catalyst proceeded effectively at $100{ }^{\circ} \mathrm{C}$ with more than $99 \%$ conversion after $1 \mathrm{~h}$. Increasing the reaction temperature to higher than $100{ }^{\circ} \mathrm{C}$ was unnecessary for the reaction, although the initial reaction rate was slightly enhanced. As expected, decreasing the reaction temperature from $100{ }^{\circ} \mathrm{C}$ to 90 or $80{ }^{\circ} \mathrm{C}$ resulted in a significant drop in the conversion of 4'-bromoacetophenone. However, the reaction still gave $95 \%$ and $71 \%$ conversions after $2 \mathrm{~h}$ at 90 and $80{ }^{\circ} \mathrm{C}$, respectively (Fig. 6). The most effective temperature range for the Suzuki reaction using the immobilized palladium catalyst in this research was in good agreement with the literature. No homo-coupling product was detected by GC analysis. It was also observed that non-functionalized superparamagnetic nanoparticles exhibited no activity, indicating the necessity of the catalyst.

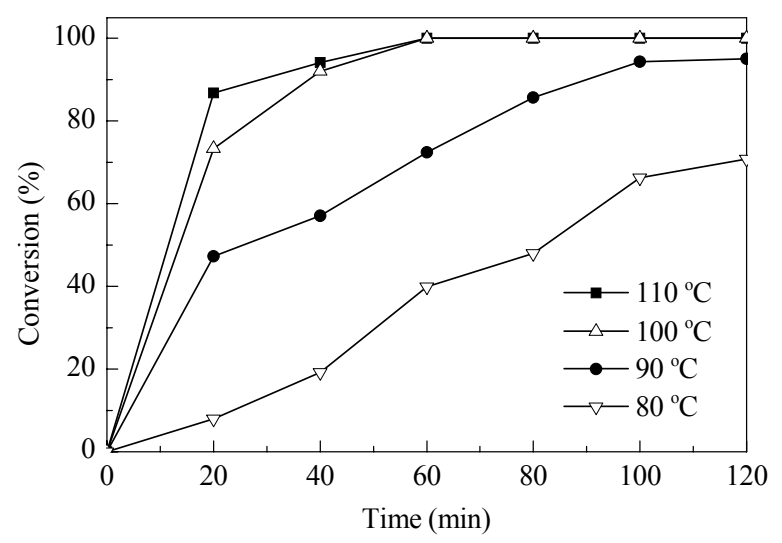

Fig. 6. Effect of temperature on reaction conversion.

The effect of catalyst concentration on the reaction conversion was studied in the range of $0.01-0.5 \mathrm{~mol} \%$ relative to 4'-bromoacetophenone. The reaction was carried out at $100{ }^{\circ} \mathrm{C}$ using DMF as the solvent and $\mathrm{K}_{3} \mathrm{PO}_{4}$ as the base. A higher catalyst concentration gave a higher reaction rate. More than $99 \%$ conversion was achieved for the reaction 
using $0.1 \mathrm{~mol} \%$ catalyst after $1 \mathrm{~h}$. As expected, increasing the catalyst concentration to $0.5 \mathrm{~mol} \%$ led to an enhancement in reaction rate, with a conversion of more than $99 \%$ after $40 \mathrm{~min}$. A lower reaction rate was observed at the catalyst concentration of $0.01 \mathrm{~mol} \%$, although the reaction could still give a conversion of $94 \%$ after $2 \mathrm{~h}$ (Fig. 7). The catalyst concentrations used in this study were therefore comparable to those of several previous reports, where the palladium concentrations were varied from less than 0.1 $\mathrm{mol} \%$ to more than $5 \mathrm{~mol} \%$ for different catalysts and substrates $[3,5,6]$. Indeed, some homogeneous palladium complexes were effective for the Suzuki reaction at a catalyst concentration as low as $0.0005 \mathrm{~mol} \%$ [77]. However, Suzuki reactions using solid catalysts require higher catalyst concentrations, normally in the range of $0.1-1 \mathrm{~mol} \%$.

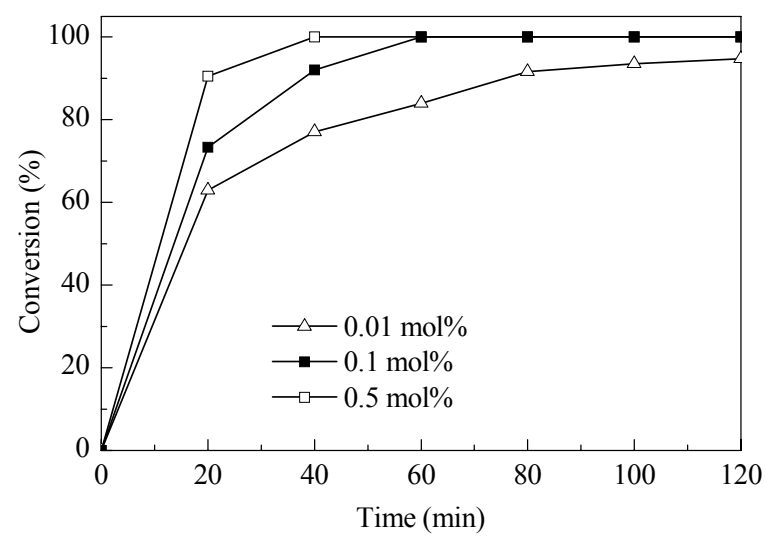

Fig. 7. Effect of catalyst concentration on reaction conversion.

The reaction was then extended to the Suzuki reaction of several aryl bromides containing the bromo group at different positions, and with either electron-withdrawing or electron-donating groups. The reaction was carried out at $100{ }^{\circ} \mathrm{C}$ using $0.1 \mathrm{~mol} \%$ catalyst in the presence of $\mathrm{K}_{3} \mathrm{PO}_{4}$ as the base. Interestingly, it was found that the Suzuki reaction using the immobilized palladium catalyst gave a selectivity for 4'-bromoacetophenone that was higher than those for the corresponding 3'- and 2'-isomers. The reaction of the 3 '-isomer gave $84 \%$ conversion after $2 \mathrm{~h}$, while quantitative conversion was achieved after $1 \mathrm{~h}$ for the 4 '-isomer. Furthermore, there was $50 \%$ unreacted starting material in the case of the 2'-isomer, which led us to believe that increased steric bulk at the 2-position inhibited substitution (Fig. 8) [78]. As expected, it was observed that the presence of an electron-withdrawing group on the benzene ring of the aryl bromide significantly accelerated the Suzuki reaction, while the presence of an electron-donating group resulted in a significantly drop in reaction rate. The reactivity of aryl bromides in the Suzuki reaction with phenylboronic acid was in the order 4-bromonitrobenzene > 4-bromobenzonitrile $>$ 4'-bromoacetophenone >

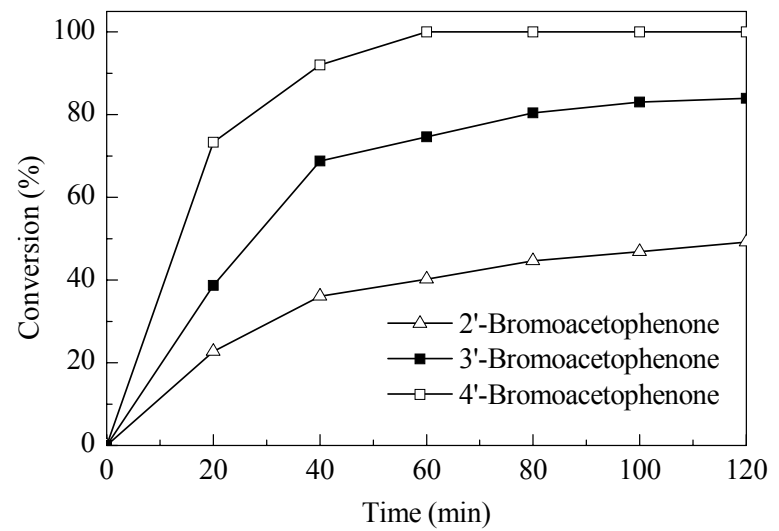

Fig. 8. Effect of bromine substitution position on reaction conversion.

4-bromoflorobenzene $>$ bromobenzene $>$ 4-bromotoluene $>$ 4-bromoanisole (Fig. 9).

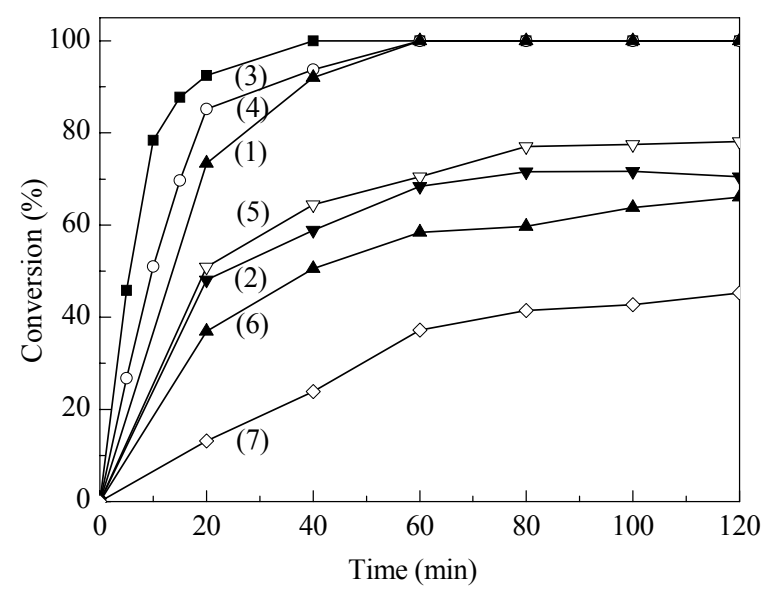

Fig. 9. Effect of aryl bromide on reaction conversion. (1) 4'-Bromoacetophenone; (2) Bromobenzene; (3) 4-Bromonitrobenzene; (4) 4-Bromo-benzonitrile; (5) 4-Bromoflorobenzene; (6) 4-Bromotoluene; (7) 4-Bromoanisole.

It was also observed that 4'-iodoacetophenone was more reactive than 4'-bromoacetophenone. As expected, the Heck reaction of 4'-chloroacetophenone proceeded with a significantly slower rate than was the case with 4'-bromoacetophenone, and a conversion of only $14 \%$ was obtained after $6 \mathrm{~h}$ (Fig. 10). Chloroarenes were previously reported to be inactive for several palladium-catalyzed cross-coupling reactions [8]. The Suzuki reaction of 4'-bromoacetophenone was also carried using different substituted phenylboronic acids. It was found that the reactivity of the phenylboronic acids with 4'-bromoacetophenone was in the order 4-methoxyphenylboronic acid $>$ phenylboronic acid $>4$-fluorophenylboronic acid $>4$-chlorophenylboronic acid (Fig. 11). However, the reaction could only proceed to $90 \%$ conversion in these cases. It was previously reported 


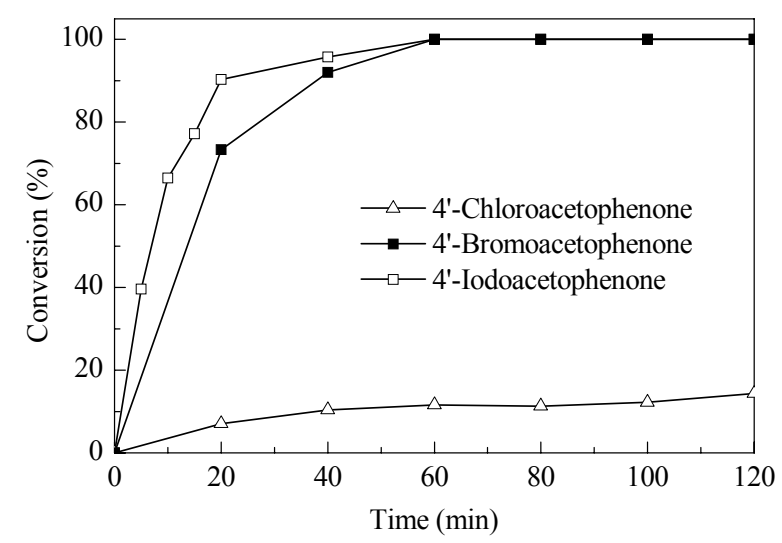

Fig. 10. Effect of the halogen in arylhalide on reaction conversion.

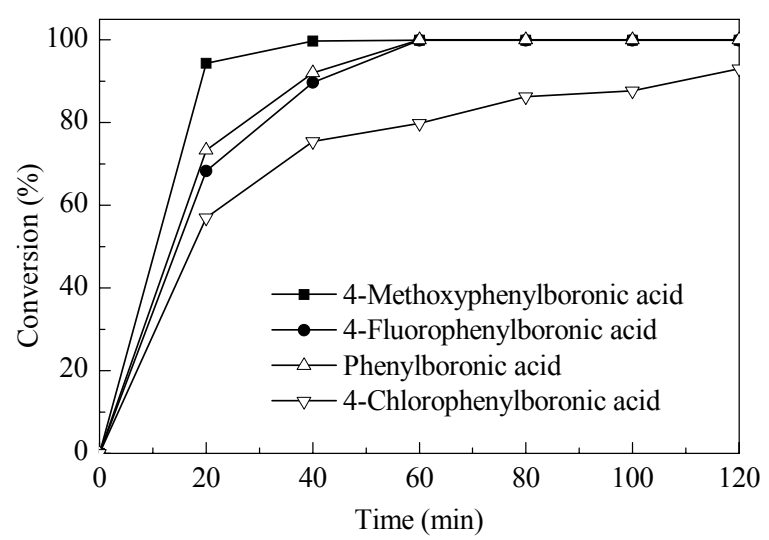

Fig. 11. Effect of substituted phenylboronic acids on reaction conversions.

that no significant difference in reaction rate was observed for the Suzuki reaction using different substituted phenylboronic acids [44,76].

As mentioned earlier, using a similar approach for palladium immobilization on superparamagnetic nanoparticles, the catalytic activity in the Suzuki reaction was significantly improved when the tether in the catalyst structure was extended. The activity of the immobilized palladium catalyst obtained using catalyst B was compared to that of the case when catalyst A was used. The Suzuki reaction was carried out at $100{ }^{\circ} \mathrm{C}$ using $0.1 \mathrm{~mol} \%$ palladium catalyst. It was found that the reaction of 4-bromonitrobenzene with phenylboronic acid using catalyst B gave more than $99 \%$ conversion after $40 \mathrm{~min}$, while $92 \%$ conversion was obtained for the case of catalyst A. The difference in catalytic activity between these two catalysts was also observed for the Suzuki reactions of 4'-bromoacetophenone, 4-bromotoluene, and 4-bromoanisole, respectively, with phenylboronic acid (Fig. 12). This difference indicated that although the catalytically active sites were the same, the tether between the catalyst support and the active site should also be taken into account. These results can be rationalized by that catalyst $\mathrm{B}$ possessed an active centre that is more

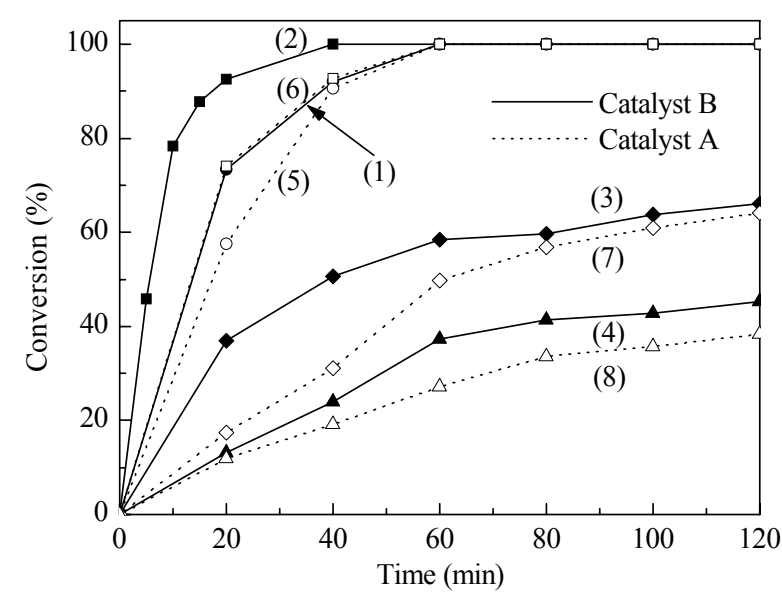

Fig. 12. Comparison of catalyst A and catalyst B. (1) and (5) 4'-Bromoacetophenone; (2) and (6) 4-Bromonitrobenzene; (3) and (7) 4-Bromotoluene; (4) and (8) 4-Bromoanisole.

accessible to the reactants because of the more extended chain tether as compared to the case of catalyst A [79]. Moreover, there was a basic nitrogen atom on the tether chain of catalyst $\mathrm{B}$, and this nitrogen atom can have a positive effect on the stability of the palladium catalyst. It was previously reported that the presence of an amine can increase the stability of the palladium catalyst in the Suzuki and the Heck reactions $[6,8]$. The effect of the nitrogen atom on the catalytic activity in the Suzuki reaction using catalyst B still needs further investigation.

For a liquid-phase reaction using solid catalysts, an important issue is the possibility that some active sites can get leached [34]. After the catalyst was removed from the reaction mixture by a small magnet, the solution was analyzed by ICP-MS. The palladium concentration in the solution was shown to be as low as $2 \mathrm{ppm}$. A minimal loss of palladium into solution in the Suzuki and Heck reactions was previously observed for the palladium catalyst immobilized on superparamagnetic nanoparticles [47]. A small amount of palladium was previously detected in the solution of the Carbonylative Sonogashira reaction with a superparamagnetic nanoparticles-supported palladium catalyst [49]. However, it was also reported that no palladium was detected in the reaction solution for other superparamagnetic nanoparticles-supported palladium catalysts [46,51]. In order to determine if leaching was a problem for the Suzuki reaction using the immobilized palladium catalyst, an experiment was performed to estimate the contribution of leached active species to the total reaction conversion. This was done by performing magnetic decantation during the course of the reaction to remove the solid catalyst. A reaction conversion that continued increasing after the solid catalyst was removed would indicate that the real active species was leached palladium rather than the solid catalyst. 
The reaction mixture that used $0.01 \mathrm{~mol} \%$ fresh catalyst at $100{ }^{\circ} \mathrm{C}$ was separated from the solid catalyst after $20 \mathrm{~min}$ reaction time by magnetic decantation. The reaction solution was then transferred to a new reactor vessel and stirred for an additional $100 \mathrm{~min}$ at $100{ }^{\circ} \mathrm{C}$. Aliquots were sampled at different time intervals and analyzed by GC. Within experimental error, no further conversion was observed after the solid catalyst was removed from the reaction mixture. This result indicated that there was no contribution from leached palladium, and that reaction was possible in the presence of the immobilized palladium catalyst (Fig. 13). It was previously proposed that the reaction using magnetic nanoparticles-supported palladium catalysts proceeded on the catalyst surface and dissolved palladium species did not catalyze the reaction [51]. In other cases, it was reported that active palladium species were dissolved from the solid catalyst during the course of the reaction and partially or completely reprecipitated onto the magnetic nanoparticles at the end of the reaction [49]. Further studies are needed to elucidate the real active species in the Suzuki reaction using the immobilized palladium catalyst.

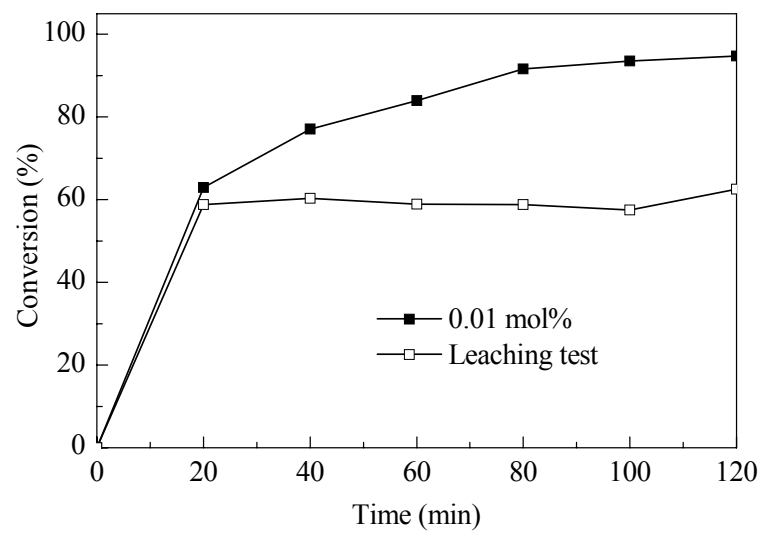

Fig. 13. Leaching test of the immobilized palladium catalyst.

Another point of great concern for immobilized catalysts is the ease of separation as well as the deactivation and reusability of the catalyst. The catalyst should be recovered and reused many times before it deactivates. At the same time, catalyst recovery can also reduce environmental pollution caused by the heavy metals used in the catalyst systems $[8,9]$. The immobilized palladium catalyst was therefore investigated for recoverability and reusability over eleven runs. After each run using $0.1 \mathrm{~mol} \%$ catalyst at $100{ }^{\circ} \mathrm{C}$ for 2 $\mathrm{h}$ in the presence of $\mathrm{K}_{3} \mathrm{PO}_{4}$, an external magnetic field was applied to the glass reaction vessel containing the magnetic nanoparticles using a small permanent magnet. The reaction solution was then easily removed from the reaction vessel by decantation while the magnet held the superparamagnetic nanoparticles inside the vessel. The magnetic catalyst was washed with acetone, deionized water, and then acetone to remove physisorbed reagents, dried under vacuum at room temperature overnight, and reused in under identical conditions to the first run. It was found that the immobilized palladium catalyst can be recovered and reused several times without significant degradation in catalytic activity. A conversion of $94 \%$ was still achieved in the 11 th run (Fig. 14(a)). Kinetic studies indicated that the catalytic activity of the immobilized palladium catalyst in the Suzuki reaction decreased slightly after each use, although complete reaction was still observed after $2 \mathrm{~h}$ (Fig. 14(b)). It was previously reported that no loss of activity was observed for several reused immobilized palladium catalysts in the Suzuki reaction, but no kinetic data was provided, and only the conversions at the end of the experiment were given $[44,47]$. Unfortunately, a stable activity cannot be proved by reporting only similar reaction conversions at long times. Kinetic studies are the true test of catalyst deactivation [34].
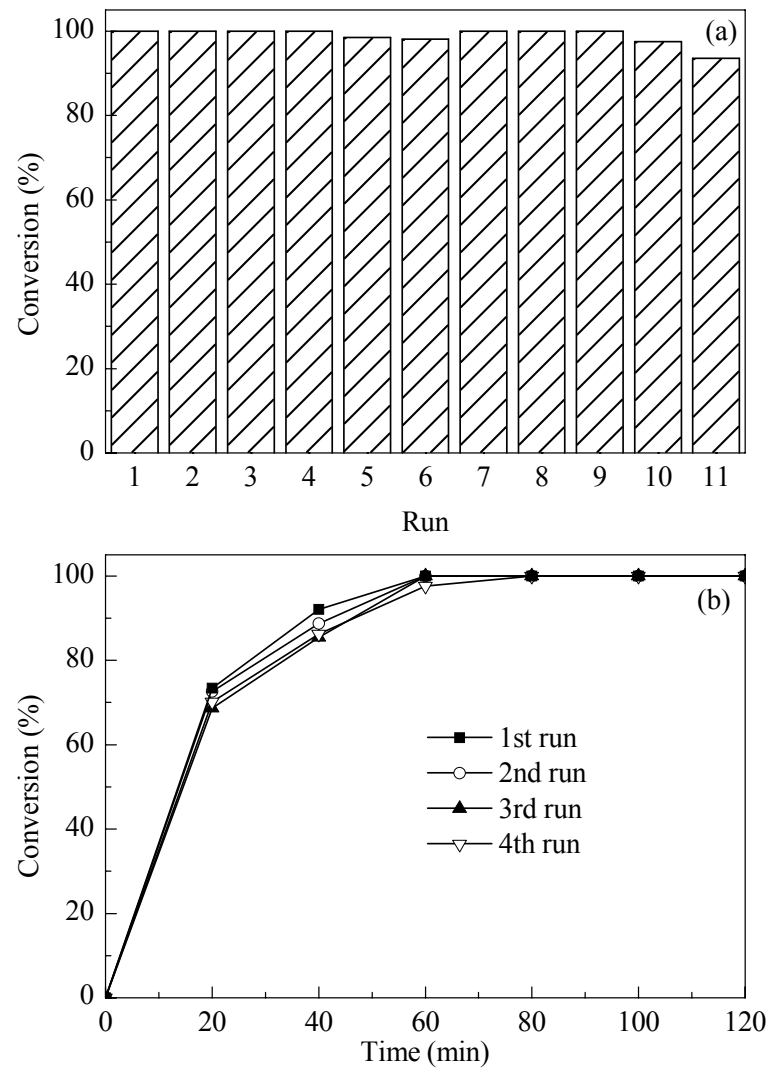

Fig. 14. Recycling studies of the immobilized palladium catalyst.

\section{Conclusions}

A palladium catalyst immobilized on superparamagnetic nanoparticles $\left(\mathrm{CoFe}_{2} \mathrm{O}_{4}\right)$ was synthesized and characterized. It was used without added phosphine ligands as a catalyst for the Suzuki cross-coupling reaction of several aryl bromides with phenylboronic acid. For the same active species, the catalytic activity in the Suzuki reaction can be signifi- 
cantly improved when the tether in the catalyst structure was extended. The recovery of the catalyst was easily achieved by simple magnetic decantation using a magnet. The immobilized palladium catalyst can be reused several times without significant degradation in catalytic activity. The magnetic nanoparticles offer advantages over conventional catalyst supports and should be of interest to the chemical industry. Current research in our laboratory is directed at the design and immobilization of several catalysts on superparamagnetic nanoparticles for a wide range of organic transformations.

\section{References}

1 Paul S, Clark J H. Green Chem, 2003, 5: 635

2 Nicolaou K C, Bulger P G, Sarlah D. Angew Chem, Int Ed, 2005, 44: 4442

3 Miyaura N, Suzuki A. Chem Rev, 1995, 95: 2457

4 Cai M, Sha J, Xu Q. J Mol Catal A, 2007, 268: 82

5 Bellina F, Carpita A, Rossi R. Synthesis, 2004: 2419

6 Phan N T S, van der Sluys M, Jones C W. Adv Synth Catal, 2006, 348: 609

7 Corbet J-P, Mignani G. Chem Rev, 2006, 106: 2651

8 Beletskaya I P, Cheprakov A V. Chem Rev, 2000, 100: 3009

9 Leadbeater N E, Marco M. Chem Rev, 2002, 102: 3217

10 Kim J-W, Kim J-H, Lee D-H, Lee Y-S. Tetrahedron Lett, 2006, 47: 4745

11 Islam S M, Mondal P, Roy A S, Mondal S, Hossain D. Tetrahedron Lett, 2010, 51: 2067

12 Phan N T S, Styring P. Green Chem, 2008, 10: 1055

13 Karimi B, Akhavan P F. Chem Commun, 2009: 3750

14 Yang H, Han X, Li G, Ma Z, Hao Y. J Phys Chem C, 2010, 114: 22221

15 Al-Hashimi M, Qazi A, Sullivan A C, Wilson J R H. J Mol Catal A, 2007, 278: 160

16 Glasspoole B W, Webb J D, Crudden C M. J Catal, 2009, 265: 148

17 Jana S, Haldar S, Koner S. Tetrahedron Lett, 2009, 50: 4820

18 Qiu H, Sarkar S M, Lee D-H, Jin M-J. Green Chem, 2008, 10: 37

19 Shi S, Zhang Y. Green Chem, 2008, 10: 868

20 Yang H, Han X, Ma Z, Wang R, Liu J, Ji X. Green Chem, 2010, 12: 441

21 Dhara K, Sarkar K, Srimani D, Saha S K, Chattopadhyay P, Bhaumik A. Dalton Trans, 2010, 39: 6395

22 Okumura K, Tomiyama T, Okuda S, Yoshida H, Niwa M. J Catal, 2010, 273: 156

23 Durap F, Rakap M, Aydemir M, Özkar S, Appl Catal A, 2010, 382: 339

24 Jin M-J, Taher A, Kang H-J, Choi M, Ryoo R. Green Chem, 2009, 11: 309

25 Trilla M, Pleixats R, Man M W C, Bied C, Moreau J J E. Tetrahedron Lett, 2006, 47: 2399

26 Blanco B, Brissart M, Moreno-Mañas M, Pleixats R, Mehdi A,
Reyé C, Bouquillon S, Hénin F, Muzart J. Appl Catal A, 2006, 297: 117

27 Scheuermann G M, Rumi L, Steurer P, Bannwarth W, Mülhaupt R. J Am Chem Soc, 2009, 131: 8262

28 Søbjerg L S, Gauthier D, Lindhardt A T, Bunge M, Finster K, Meyer R L, Skrydstrup T. Green Chem, 2009, 12: 2041

29 Prastaro A, Ceci P, Chiancone E, Boffi A, Cirilli R, Colone M, Fabrizi G, Stringaro A, Cacchi S. Green Chem, 2009, 11: 1929

30 Chattopadhyay K, Dey R, Ranu B C. Tetrahedron Lett, 2009, 50: 3164

31 Das D D, Sayari A. J Catal, 2007, 246: 60

32 Yan W, Mahurin S M, Pan Z, Overbury S H, Dai S. J Am Chem Soc, 2005, 127: 10480

33 Astruc D, Lu F, Aranzaes J R. Angew Chem, Int Ed, 2005, 44: 7852

34 Phan N T S, Jones C W. J Mol Catal A, 2006, 253: 123

35 Phan N T S, Gill C S, Nguyen J V, Zhang Z J, Jones C W. Angew Chem, Int Ed, 2006, 45: 2209

36 Lim C W, Lee I S. Nano Today, 2010, 5: 412

37 Shylesh S, Schunemann V, Thiel W R. Angew Chem, Int Ed, 2010, 49: 3428

38 Yoon T-J, Lee W, Oh Y-S, Lee J-K. New J Chem, 2003, 27: 227

39 Polshettiwar V, Baruwati B, Varma R S. Green Chem, 2009, 11: 127

40 Lu A H, Schmidt W, Matoussevitch N, Bonnemann H, Spliethoff B, Tesche B, Bill E, Kiefer W, Schuth F. Angew Chem, Int $E d, 2004,43: 4303$

41 Hu A, Yee G T, Lin W. J Am Chem Soc, 2005, 127: 12486

42 Panella B, Vargas A, Baiker A. J Catal, 2009, 261: 88.

43 Niu F, Zhang L, Luo S-Z, Song W-G. Chem Commun, 2010, 46: 1109

44 Stevens P D, Fan J, Gardimalla H M R, Yen M, Gao Y. Org Lett, 2005, 7: 2085

45 Laska U, Frost C G, Price G J, Plucinski P K. J Catal, 2009, 268: 318

46 Zhang Y-Q, Wei X-W, Yu R. Catal Lett, 2010, 135: 256

47 Baruwati B, Guin D, Manorama S V. Org Lett, 2007, 9: 5377

48 Yuan D, Zhang Q, Dou J. Catal Commun, 2010, 11: 606

49 Liu J, Peng X, Sun W, Zhao Y, Xia C. Org Lett, 2008, 10: 3933

50 Phan N T S, Le H V. J Mol Catal A, 2011, 334: 130

51 Hara T, Kaneta T, Mori K, Mitsudome T, Mizugaki T, Ebitani K, Kaneda K. Green Chem, 2007, 9: 1246

52 Zhang S, Zhao X, Niu H, Shi Y, Cai Y, Jiang G. J Hazard Mater, 2009, 167: 560

53 Dutta B, Jana S, Bhattacharjee A, Gütlich P, Iijima S-I, Koner S. Inorg Chim Acta, 2010, 363: 696

54 Oliveira R L, Kiyohara P K, Rossi L M. Green Chem, 2010, 12: 144

55 Long W, Gill C S, Choi S, Jones C W. Dalton Trans, 2010, 39: 1470

56 Che C, Li W, Lin S, Chen J, Zheng J, Wu J-C, Zheng Q, Zhang G, Yang Z, Jiang B. Chem Commun, 2009: 5990 
57 Zheng X, Luo S, Zhang L, Cheng J-P. Green Chem, 2009, 11: 455

58 Gao X, Yu K M K, Tam K Y, Tsang S K. Chem Commun, 2003: 2998

59 Netto C G C M, Andrade L H, Toma H E. Tetrahedron: Asymmetry, 2009, 20: 2299

60 Jiang Y, Guo C, Xia H, Mahmood I, Liu C, Liu H. J Mol Catal B, 2009, 58: 103

61 Lee K S, Woo M H, Kim H S, Lee E Y, Lee I S. Chem Commun, 2009: 3780

62 Shen X C, Fang X Z, Zhou Y H, Liang H. Chem Lett, 2004, 33: 1468

63 Gronnow M J, Luque R, Macquarrie D J, Clark J H. Green Chem, 2005, 7: 552

64 Choudhary D, Paul S, Guptaa R, Clark J H. Green Chem, 2006, 8: 479

65 Rondinone A J, Samia A C S, Zhang Z J. J Phys Chem B, 1999, 103: 6876

66 Lia X, Kutal C. J Alloy Compd, 2003, 349: 264

67 Gill C S, Price B A, Jones C W. J Catal, 2007, 251: 145
68 Ma M, Zhang Y, Yu W, Shen H Y, Zhang H Q, Gu N. Colloids Surf A, 2003, 212: 219

69 Shen X C, Fang X Z, Zhou Y H, Liang H. Chem Lett, 2004, 33: 1468

70 Watanabe T, Miyaura N, Suzuki A. Synlett, 1992: 207

71 Zhong C, Sasaki T, Tada M, Iwasawa Y. J Catal, 2006, 242: 357

72 Sicre C, Alonso-Gómez J-L, Cid M M. Tetrahedron, 2006, 62: 11063

73 Schröter S, Stock C, Bach T. Tetrahedron, 2005, 61: 2245

74 Fairlamb I J S. Annu Rep Prog Chem, Sect B, 2005, 101: 69

75 Das P, Bora U, Tairai A, Sharma C. Tetrahedron Lett, 2010, 51: 1479

76 Guo M, Zhang Q. Tetrahedron Lett, 2009, 50: 1965

77 Bedford R B, Hazelwood S L, Fimmert M E, Albisson D A, Draper S M, Scully P N, Coles S J, Hursthouse M B. Chem-Eur J, 2003, 9: 3216

78 Phan N T S, Brown D H, Adams H, Sharon E S, Styring P. Dalton Trans, 2004: 1348

79 Phan N T S, Brown D H, Styring P. Green Chem, 2004, 6: 526 